\title{
Research on the Influencing Factors and Driving Paths of Public Opinions Reversed by Public Emergencies: Clear Set Qualitative Comparative Analysis Based on 30 Cases from 2014 to 2020 (QCA)
}

\author{
Yanling Li and Xianwen Wu \\ College of Public Management \& Law, Hunan Agricultural University, Changsha, China \\ Correspondence should be addressed to Xianwen Wu; wuxw1997@stu.hunau.edu.cn
}

Received 17 January 2022; Revised 7 February 2022; Accepted 8 February 2022; Published 23 February 2022

Academic Editor: Kalidoss Rajakani

Copyright (C) 2022 Yanling $\mathrm{Li}$ and Xianwen Wu. This is an open access article distributed under the Creative Commons Attribution License, which permits unrestricted use, distribution, and reproduction in any medium, provided the original work is properly cited.

\begin{abstract}
Studying the influencing factors and identifying the driving path of public opinion reversal have important practical significance for effectively avoiding the risk of public opinion reversal. Combined with the theory of actor network, the analysis shows that 7 important factors in the public opinion reversal are the antecedent conditions of public opinion reversal in public emergencies. Qualitative comparative analysis identifies the internal motivation and driving path of the reversal of online public opinion. Four core driving paths are obtained. Through the analysis of different condition combination paths, the conclusion is reached: the role of opinion leaders in reversing public opinion in public emergencies is limited; the central government must pay attention to the core role of the response; be wary of graphics and text formal dissemination; it is necessary to strengthen the check and review and standardize the management of the first issuer.
\end{abstract}

\section{Introduction}

As the population of netizens continues to grow, the information on the Internet becomes more and more difficult to distinguish between true and false, and the phenomenon of public opinion reversal has become more frequent [1]. The reversal of network public opinion has the negative effects of dispelling the rationality of the audience, overdrafting the credibility of the media, and affecting social harmony and stability [2-4]. Identifying the core conditions and combination paths of public opinion reversal in public emergencies and clarifying the internal mechanism of network public opinion reversal are an important basis for avoiding public opinion risks in public emergencies.

The reversal of public opinion in emergencies is different from ordinary public opinion [1]. Due to the reversal of the truth of the event, the frequency of public opinion outbreaks increases, the time for public opinion is prolonged, and the difficulty of public opinion governance becomes more difficult [2-4]. The public was plunged into chaos due to the confusing reversal incident. The credibility and authority of the government and the news media were questioned during a reversal of public opinion, which may cause real tragedies (such as the "Deyang female doctor suicide" incident) and trigger society. Identifying the core conditions and combination paths of public opinion reversal in public emergencies and clarifying the internal mechanism of public opinion reversal on the network are important foundations for avoiding the risk of public opinion in public emergencies.

The existing research on the reversal of online public opinion provides a good reference for this article. However, there is still room for expansion: First, there are few researches on the influencing factors of public opinion reversal in public emergencies, and the driving path of public opinion reversal in public emergencies needs to be clarified; second, there are many public opinion reversals in public emergencies. There is little attention to the configuration relationship of the interaction between the various influencing factors. Based on this, this article uses a clear set and qualitative comparative analysis of 30 public emergency cases to identify the antecedent conditions and condition combination paths of the network public opinion reversal 
TABLE 1: Research case library.

\begin{tabular}{|c|c|c|c|c|c|}
\hline Serial & Year & Name & Serial & Year & Name \\
\hline 1 & 2020 & $\begin{array}{l}\text { Shuanghuanglian oral liquid can prevent } \\
\text { the new coronavirus }\end{array}$ & 16 & 2017 & Yulin pregnant women fell from the building incident \\
\hline 2 & 2019 & Zhoukou baby lost case in Henan Province & 17 & 2016 & "Shanghai Women Fleeing Jiangxi Rural Area" incident \\
\hline 3 & 2019 & Courier kneeling incident & 18 & 2016 & Harbin sky-high fish incident \\
\hline 4 & 2019 & $\begin{array}{c}\text { Chengdu No. } 7 \text { Experimental School food safety } \\
\text { issue }\end{array}$ & 19 & 2016 & Beijing school district 460,000 per square meter? \\
\hline 5 & 2018 & Wang Fengya incident & 20 & 2016 & Auntie "Porcelain" toy car incident \\
\hline 6 & 2018 & $\begin{array}{l}\text { College entrance examination answer sheet was } \\
\text { transferred }\end{array}$ & 21 & 2016 & Lei Yang incident \\
\hline 7 & 2018 & Deyang female doctor committed suicide & 22 & 2016 & "Kidney loss? Kidney atrophy?" incident \\
\hline 8 & 2018 & Chongqing bus crash incident & 23 & 2016 & Handong puerpera left gauze incident \\
\hline 9 & 2018 & Express brother crying in the rain & 24 & 2016 & "Luo Yixiao Incident" \\
\hline 10 & 2018 & My cousin replaced college & 25 & 2018 & The post-80s white-haired secretary \\
\hline 11 & 2018 & Children in Yueqing "lost connection" & 26 & 2015 & Female college students helping the elderly who fell down \\
\hline 12 & 2017 & $\begin{array}{c}\text { Nanluo Bookstore Park Dao Caotang staged } \\
\text { a bitter drama }\end{array}$ & 27 & 2015 & Is a woman bitten by a vicious dog to save a girl? \\
\hline 13 & 2017 & College students kicked bear children in anger? & 28 & 2015 & $\begin{array}{c}\text { Violent assault on police at Qing'an Railway Station in } \\
\text { Heilongjiang }\end{array}$ \\
\hline 14 & 2017 & A 12-year-old girl was molested by two teachers & 29 & 2015 & A man beat up a female driver in Chengdu \\
\hline 15 & 2017 & "Fighting Orphans" incident & 30 & 2014 & Doctors operating room selfie \\
\hline
\end{tabular}

of public emergencies and form the driving path of the network public opinion reversal of public emergencies $[5,6]$.

\section{Research Design}

2.1. Research Case Selection. The emergencies referred to in the emergency response law refer to natural disasters, accident disasters, public health events, and social security events that occur suddenly, cause or may cause serious social harm, and require emergency response measures. Due to the explosive growth of the number of social media users in China in 2014, the case selected in this paper is the 20142020 incident as a research case for the reversal of network public opinion in public emergencies. This paper summarizes the major news reversal events in the Zhiwei event database of the Zhiwei data platform and selects 30 typical public opinion reversal events into the research case database (see Table 1). These cases involve a variety of social hotspots. The topics cover many fields such as doctor-patient relationship, official-civilian relationship, public order, and good customs.

2.2. Research Methods. This paper uses the qualitative comparative analysis (QCA) method initiated by Charles C. Ragin in 1987, which is a method based on set theory and Boolean algebra [7]. This is mainly due to the following considerations: First, this study uses 30 cases from 2014 to 2020 as the research sample. The sample size failed to reach the level of "large sample," making it difficult to obtain robust results through statistical methods. QCA is based on Boolean operations and can handle both small sample problems and medium or large sample problems. The data of this study covers various public emergencies, and the sample size is moderate and suitable for the QCA method. Second, the existing research and literature show that to explain the internal mechanism of the reversal of public opinion in public emergencies, single-case analysis or pairwise interaction analysis of factors such as netizens, events, media, and government is far from enough. QCA adopts a holistic perspective to conduct cross-case comparative analysis, so it has a good adaptability to this type of research.

\subsection{Variable Assignment and Truth Table Construction}

2.3.1. Variable Assignment. The measurement of the evolution and reversal of network public opinion in emergencies is a very complicated issue, and the time of the public opinion climax for different events is different. Referring to the result variable settings of related scholars' research on online public opinion, the outbreak time difference, that is, the time difference from the occurrence of the event to the peak of public opinion, is selected as the result variable [5]. Due to the particularity of the reversal of public opinion, the first report needs to be clarified. Therefore, the outbreak time difference is divided into prereversal and postreversal; that is, before the reversal or after the reversal, the public opinion reaches the highest peak of public opinion, and this is determined as the basis. This was used as the outcome variable for this study.Condition variables are mainly based on the combination of actor networks and the actual situation of the case. In this study, netizen factors include opinion leaders and hot topics; event factors include the form of public opinion sources and the time of reversal (The reversal time of different events varies from 24 hours to 14 days after the first report. Taking into account the proportion, average value, and median, three days are selected as the standard. In the 
TABLE 2: Assignment rule table.

\begin{tabular}{|c|c|c|c|c|c|}
\hline Variable & Explanatory variables & Statistics & Data weight & Assignment & Illustrate \\
\hline \multirow{5}{*}{ Netizen factor } & \multirow{2}{*}{ (A) Opinion leader } & No & $63.3 \%$ & 1 & \multirow{2}{*}{ Condition variable } \\
\hline & & Yes & $36.7 \%$ & 0 & \\
\hline & \multirow{3}{*}{ (B) Hot topics } & Personal safety & $46.7 \%$ & 1 & \multirow{3}{*}{ Condition variable } \\
\hline & & Economic benefit & $16.6 \%$ & 1 & \\
\hline & & Emotional appeal & $36.7 \%$ & 0 & \\
\hline \multirow{4}{*}{ Event factor } & \multirow{2}{*}{ (C) Public opinion form } & Graphic & $60.0 \%$ & 1 & \multirow{2}{*}{ Condition variable } \\
\hline & & Video & $40.0 \%$ & 0 & \\
\hline & \multirow{2}{*}{ (D) Reversal time } & Three days later & $53.3 \%$ & 1 & \multirow{2}{*}{ Condition variable } \\
\hline & & Within three days & $46.7 \%$ & 0 & \\
\hline \multirow{6}{*}{ Media factors } & \multirow{4}{*}{ (E) Starting body } & Netizens broke the news & $53.3 \%$ & 0 & \multirow{3}{*}{ Condition variable } \\
\hline & & Traditional media & $13.4 \%$ & 1 & \\
\hline & & Internet media & $33.3 \%$ & 1 & \\
\hline & & Netizens questioned & $50.0 \%$ & 0 & \multirow{3}{*}{ Condition variable } \\
\hline & \multirow[t]{2}{*}{ (F) Reason for reversal } & Media follow-up report & $23.4 \%$ & 0 & \\
\hline & & Investigation by relevant departments & $26.6 \%$ & 1 & \\
\hline \multirow{2}{*}{ Government factor } & \multirow{2}{*}{ (G) Government response } & Central & $80.0 \%$ & 1 & \multirow{2}{*}{ Condition variable } \\
\hline & & Place & $20.0 \%$ & 0 & \\
\hline \multirow{2}{*}{$S$ jet lag } & \multirow{2}{*}{ - } & Before reversal & $60.0 \%$ & 1 & \multirow{2}{*}{ Condition variable } \\
\hline & & After reversal & $40.0 \%$ & 0 & \\
\hline
\end{tabular}

study case, $45.7 \%$ of the events reversed within three days and $54.2 \%$ after three days). The government factor mainly considers the level of government response: central government media, local government media.In addition, the variables in this study were processed by dichotomy; that is, they were divided into condition variables and outcome variables, and the variable value was 1 or 0 . The variable assignment rules are shown in Table 2.

2.3.2. Truth Table Construction. After the explanatory variables and outcome variables are defined, 30 emergency cases are coded and sorted according to the steps of QCA comparative analysis, and then, the bipartite table of condition variables and outcome variables of each case can be obtained. Through the qualitative analysis software Tosmana1.6, a set of truth tables without contradictory configuration is obtained, and the result variable is "1," as shown in Table 3.

\section{Results and Discussion}

3.1. Univariate Necessity Analysis: Public Opinion Reversal Factors. Consistency and coverage analysis in QCA analysis can explore the necessary and sufficient relationship between condition variables and results and then analyze the univariate factors of public opinion reversal in emergencies. When the consistency index is greater than or equal to 0.8 , it indicates that the condition variable appears as a sufficient condition for the result variable, which can lead to the occurrence of the result variable; when the index is greater than or equal to 0.9 , the condition variable is the necessary condition for the result variable. The coverage index refers to the original coverage, which reflects the explanatory power of the condition variable to the outcome variable.
" " means "not," which is the opposite value. The calculation formula is as follows:

$$
\begin{aligned}
& \operatorname{Consistency}(\mathrm{Xi} \leq \mathrm{Yi})=\frac{\sum[\mathrm{min}(\mathrm{Xi}, \mathrm{Yi})]}{\sum \mathrm{Xi}}, \\
& \text { Coverage }(\mathrm{Xi} \leq \mathrm{Yi})=\frac{\sum[\min (\mathrm{Xi}, \mathrm{Yi})]}{\mathrm{Yi}} \text {. }
\end{aligned}
$$

In Table 4, in the necessity test, when the outcome variable is " 1 " in the consistency test, the consistency of each single variable except $G$ (the central government response) to the outcome variable does not exceed 0.8 , indicating that the central government in the single variable government response is a necessary condition for the outcome variable. In the test of coverage, each single variable is not a necessary condition. Although the central government's response is a necessary condition for the outbreak of public opinion before the reversal, the local government's response is not a necessary condition for the outbreak of public opinion after the reversal. Second, the coverage rate of $G$ (the central government response) does not exceed 0.8 , and the coverage rates of the rest of the conditional variables are also below the 0.8 level.

In the consistency test where the result variable is " 0 ," the consistency of each single variable with the result variable except $\sim F$ (questions from netizens and media follow-up reports) is more than 0.8 , indicating that the result variable is " 0 ." It is sufficient for netizens to question and media follow-up to report this conditional variable as a necessary condition. In the coverage test, the coverage rate of $\sim F$ (netizens questioned and media follow-up reports) is lower than 0.8 , and the coverage rates of other conditional 
TABLe 3: Truth table.

\begin{tabular}{|c|c|c|c|c|c|c|c|c|}
\hline $\begin{array}{l}\text { Opinion } \\
\text { leader }\end{array}$ & $\begin{array}{l}\text { Hot } \\
\text { topics }\end{array}$ & $\begin{array}{l}\text { Public opinion } \\
\text { form }\end{array}$ & $\begin{array}{l}\text { Reversal } \\
\text { time }\end{array}$ & $\begin{array}{c}\text { Starting } \\
\text { body }\end{array}$ & $\begin{array}{l}\text { Reason for } \\
\text { reversal }\end{array}$ & $\begin{array}{l}\text { Government } \\
\text { response }\end{array}$ & Jet lag & $\begin{array}{l}\text { Number } \\
\text { of cases }\end{array}$ \\
\hline 0 & 0 & 1 & 0 & 1 & 0 & 1 & 1 & 2 \\
\hline 0 & 0 & 1 & 1 & 1 & 0 & 1 & 0 & 1 \\
\hline 0 & 1 & 0 & 0 & 0 & 0 & 1 & 0 & 1 \\
\hline 0 & 1 & 0 & 1 & 0 & 0 & 1 & 0 & 1 \\
\hline 0 & 1 & 0 & 1 & 1 & 0 & 0 & 0 & 1 \\
\hline 0 & 1 & 0 & 1 & 1 & 0 & 1 & 1 & 2 \\
\hline 0 & 1 & 0 & 1 & 1 & 1 & 1 & 0 & 1 \\
\hline 0 & 1 & 1 & 1 & 0 & 0 & 0 & 0 & 1 \\
\hline 0 & 1 & 1 & 1 & 0 & 1 & 1 & 1 & 1 \\
\hline 1 & 0 & 0 & 0 & 0 & 0 & 1 & 1 & 1 \\
\hline 1 & 0 & 0 & 1 & 1 & 0 & 0 & 0 & 1 \\
\hline 1 & 0 & 1 & 0 & 0 & 0 & 1 & 0 & 1 \\
\hline 1 & 0 & 1 & 0 & 1 & 0 & 1 & 1 & 1 \\
\hline 1 & 0 & 1 & 0 & 1 & 1 & 1 & 1 & 1 \\
\hline 1 & 0 & 1 & 1 & 0 & 0 & 1 & 1 & 1 \\
\hline 1 & 0 & 1 & 1 & 0 & 1 & 1 & 1 & 1 \\
\hline 1 & 0 & 1 & 1 & 1 & 1 & 1 & 0 & 1 \\
\hline 1 & 1 & 0 & 0 & 0 & 0 & 0 & 0 & 2 \\
\hline 1 & 1 & 0 & 0 & 0 & 0 & 1 & 0 & 1 \\
\hline 1 & 1 & 0 & 0 & 0 & 1 & 1 & 1 & 1 \\
\hline 1 & 1 & 1 & 0 & 0 & 1 & 1 & 1 & 1 \\
\hline 1 & 1 & 1 & 0 & 1 & 0 & 1 & 1 & 2 \\
\hline 1 & 1 & 1 & 1 & 0 & 0 & 0 & 1 & 1 \\
\hline 1 & 1 & 1 & 1 & 0 & 0 & 1 & 1 & 1 \\
\hline 1 & 1 & 1 & 1 & 0 & 1 & 1 & 1 & 1 \\
\hline 1 & 1 & 1 & 1 & 1 & 0 & 1 & 1 & 1 \\
\hline
\end{tabular}

Source: generated by the fsQCA software.

variables are also high and low, and the explanatory power is not very strong. It can be seen that these single variables alone cannot make the reversal of public opinion subside faster; that is, its propagation and evolution are complex joint effects of multiple factors.

3.2. Consistency and Coverage Analysis of Condition Combinations. In this paper, the fsQCA3.0 software is used to perform the Boolean minimization operation on the truth table, and the original consistency threshold is set to 0.8 , the PRI consistency threshold is set to 0.70 , and the case frequency threshold is set to 1 . Due to the lack of evidence and theory that the condition variables affect the exact direction of the results, in the counterfactual analysis of this study, it is assumed that the presence or absence of a single condition variable can affect the time difference between events reaching the peak of public opinion. QCA analysis provides three solutions for the study, namely, complex solution, intermediate solution, and parsimonious solution. The conclusion obtained from the intermediate solution between the complex solution and the intermediate solution has good enlightenment and universality and is usually regarded as QCA. The optimal solution is reported and interpreted in the study [8]. The consistency and coverage analysis results of the condition combinations are shown in Tables 5 and 6 . No matter whether the result variable is " 1 " or " 0 ," there are 9 corresponding condition combinations for the two outcome variables, and the consistency of each combination is consistent. The overall coverage and overall consistency are all 1 , and they are all necessary conditions to be greater than the originality threshold of 0.8 .

3.3. Configuration Analysis: The Driving Path of Reversing Public Opinion. Through the comparison of the nested relationship between the intermediate solution and the reduced solution, identify the core condition of each solution: the condition that appears in both the intermediate solution and the reduced solution is the core condition of the solution, and the condition that only appears in the intermediate solution is the edge condition (twenty-one). The QCA analysis results are shown in Tables 7 and 8 . Among them, there are 9 configurations ( $S 1 \sim S 9$ ) that reach the highest peak of public opinion before the reversal, of which (S1, S3), (S2, S4), (S5, S7), and (S6, S9) constitute the second order, etc. Price configuration, that is, their core conditions are the same 
TABLE 4: Necessity test of individual conditions of QCA method.

\begin{tabular}{|c|c|c|c|c|}
\hline \multirow[t]{2}{*}{ Condition variable } & \multicolumn{2}{|c|}{$\begin{array}{l}\text { Outcome variable }=\text { reach the peak of } \\
\text { public opinion before reversal }\end{array}$} & \multicolumn{2}{|c|}{$\begin{array}{c}\text { Outcome variable }=\text { reach the peak of } \\
\text { public opinion after reversal }\end{array}$} \\
\hline & Consistency & Coverage & Consistency & Coverage \\
\hline$A$ & 0.722222 & 0.684211 & 0.500000 & 0.315789 \\
\hline$\sim A$ & 0.277778 & 0.454545 & 0.500000 & 0.545455 \\
\hline$B$ & 0.611111 & 0.578947 & 0.666667 & 0.421053 \\
\hline$\sim B$ & 0.388889 & 0.636364 & 0.333333 & 0.363636 \\
\hline$C$ & 0.777778 & 0.777778 & 0.333333 & 0.222222 \\
\hline$\sim C$ & 0.222222 & 0.333333 & 0.666667 & 0.666667 \\
\hline$D$ & 0.500000 & 0.562500 & 0.583333 & 0.437500 \\
\hline$\sim D$ & 0.500000 & 0.642857 & 0.416667 & 0.357143 \\
\hline E & 0.500000 & 0.642857 & 0.416667 & 0.357143 \\
\hline$\sim E$ & 0.500000 & 0.562500 & 0.583333 & 0.437500 \\
\hline$F$ & 0.333333 & 0.750000 & 0.166667 & 0.250000 \\
\hline$\sim F$ & 0.666667 & 0.545455 & 0.833333 & 0.454545 \\
\hline$G$ & 0.944444 & 0.708333 & 0.583333 & 0.291667 \\
\hline$\sim G$ & 0.055556 & 0.166667 & 0.416667 & 0.833333 \\
\hline
\end{tabular}

Source: generated by the fsQCA software.

[9]; the next step will be to further analyze the driving path of public emergencies reversing the spread of public opinion.

It can be seen from Table 7 that the original coverage rate of all paths is higher than the unique coverage rate, indicating that there are support cases that conform to multiple causal paths [10]. Through the integration of multiple causal paths, five core drive paths are finally simplified, namely, $A$ $* C * D * \sim E *(G+B * \sim F)$ (path 1$), \sim B * C * \sim D * E *$ $G *(\sim F+A)$ (path 2), $B * \sim E * F * G *(A * \sim D+C * D$ *) (path 3), $B * E * \sim F * G *(A * C+\sim A * \sim C * D)$ (path 4 ), and $A * \sim B * \sim C * \sim D * \sim E * \sim F * G$ (path 5). Among them, the driving paths with higher case coverage are path 1 , path 2 , path 3 , and path 4 .

First, from the simplified path one, it can be seen that no opinion leader $*$ graphic form $*$ reversal after three days $*$ netizens broke the news that played a core element in this path. This path means that after an emergency occurs, the netizens first broke the news and released it on the Internet [11]. Without the guidance and participation of opinion leaders, the incident reversed three days later, and the peak of public opinion arrived before the reversal. In terms of specific cases, the food safety incident of Chengdu No. 7 Experimental School, the incident of "Shanghai women escaping from Jiangxi countryside," the incident of sky-high fish in Harbin, and the incident of female college students assisting the elderly who fell over and other emergencies are typical representatives of this path. In these emergencies, netizens, as the driving subject, have different degrees of exaggeration and misinterpretation. This has caused the information audience to form a variety of negative emotions and spread them, resulting in the emergence of online public opinion reaching the highest level before the reversal peak.

Second, it can be seen from the simplified path two that emotional appeals $*$ graphic forms $*$ reversed within three days $*$ media firsts $*$ the central government's response has played a core element in this path. This path means that after an emergency occurs, it is reported and displayed by online media or traditional media [12]. The incident reverses within three days, and the peak of public opinion arrives before the reversal. Sudden events such as the Wang Fengya incident, Piao Dao Caotang in Nanluo Bookstore staged a bitter drama, a white-haired secretary born in the 1980s, and a woman being bitten by a vicious dog to save a girl are all typical examples of this path. These events were first shown on WeChat, Weibo, forums, blogs, short video platforms, and other online media and traditional media platforms, and they reversed within three days. At this time, the public opinion of the event reached its peak before the reversal.

Third, from the simplified path three, it can be seen that personal safety and economic interest issues $*$ netizens broke the news $*$ relevant department investigations $*$ the central government's response played a core element in this path. This path means that when an emergency occurs, netizens release information and reveal the news on the Internet, and the incident can be reversed under media follow-up reports and investigations by relevant departments [13]. At this time, public opinion reaches its peak before the reversal. Such as the food safety problem of Chengdu No. 7 Experimental School, the courier brother crying in the rain, the "lost connection" of the children in Yueqing, and the molestation of a 12-year-old girl by two teachers are all typical examples of this path. In these incidents, investigations by the relevant departments have made the truth of the incident appear faster, but it will also gather more followers and expand the scope of the incident, which will lead to the peak of the public opinion of the incident before the reversal.

Fourth, from the simplified path four, it can be seen that personal safety and economic benefits issues $*$ media initials 
TABLE 5: Consistency and coverage analysis of result variable $=1$.

\begin{tabular}{|c|c|c|c|c|c|c|}
\hline Combination & $\begin{array}{l}\text { Variable combinations of } \\
\text { intermediate solutions }\end{array}$ & $\begin{array}{l}\text { Original } \\
\text { coverage }\end{array}$ & $\begin{array}{l}\text { Unique } \\
\text { coverage }\end{array}$ & $\begin{array}{l}\text { Combinatorial } \\
\text { consistency }\end{array}$ & $\begin{array}{c}\text { Overall } \\
\text { coverage }\end{array}$ & $\begin{array}{c}\text { Overall } \\
\text { consistency }\end{array}$ \\
\hline S1 & $A^{*} C^{*} D^{*} \sim E^{*} G$ & 0.222222 & 0.111111 & 1 & \multirow{9}{*}{1} & \multirow{9}{*}{1} \\
\hline S2 & $\sim B^{*} C^{*} \sim D^{*} E^{*} \sim F^{*} G$ & 0.166667 & 0.111111 & 1 & & \\
\hline S3 & $A^{*} B^{*} C^{*} D^{*} \sim E^{*} \sim F$ & 0.111111 & 0.0555556 & 1 & & \\
\hline S4 & $A^{*} \sim B^{*} C^{*} \sim D^{*} E^{*} G$ & 0.111111 & 0.0555556 & 1 & & \\
\hline S5 & $A^{*} B^{*} \sim D^{*} \sim E^{*} F^{*} G$ & 0.111111 & 0.111111 & 1 & & \\
\hline S6 & $A^{*} B^{*} C^{*} E^{*} \sim F^{*} G$ & 0.166667 & 0.166667 & 1 & & \\
\hline S7 & $B^{*} C^{*} D^{*} \sim E^{*} F^{*} G$ & 0.111111 & 0.0555556 & 1 & & \\
\hline S8 & $A^{*} \sim B^{*} \sim C^{*} \sim D^{*} \sim E^{*} \sim F^{*} G$ & 0.0555556 & 0.0555556 & 1 & & \\
\hline S9 & $\sim A^{*} B^{*} \sim C^{*} D^{*} E^{*} \sim F^{*} G$ & 0.111111 & 0.111111 & 1 & & \\
\hline
\end{tabular}

Source: generated by the fsQCA software.

TABLE 6: Consistency and coverage analysis of result variable $=0$.

\begin{tabular}{|c|c|c|c|c|c|c|}
\hline Combination & $\begin{array}{l}\text { Variable combinations of } \\
\text { intermediate solutions }\end{array}$ & $\begin{array}{l}\text { Original } \\
\text { coverage }\end{array}$ & $\begin{array}{l}\text { Unique } \\
\text { coverage }\end{array}$ & $\begin{array}{l}\text { Combinatorial } \\
\text { consistency }\end{array}$ & $\begin{array}{c}\text { Overall } \\
\text { coverage }\end{array}$ & $\begin{array}{c}\text { Overall } \\
\text { consistency }\end{array}$ \\
\hline NS1 & $A^{*} B^{*} \sim C^{*} \sim D^{*} \sim E^{*} \sim F$ & 0.25 & 0.25 & 1 & & \\
\hline NS2 & $\sim A^{*} B^{*} \sim C^{*} \sim E^{*} \sim F^{*} G$ & 0.166667 & 0.166667 & 1 & & \\
\hline NS3 & $\sim A^{*} B^{*} C^{*} D^{*} \sim E^{*} \sim F^{*} \sim G$ & 0.0833333 & 0.0833333 & 1 & & \\
\hline NS4 & $A^{*} \sim B^{*} \sim C^{*} D^{*} E^{*} \sim F^{*} \sim G$ & 0.0833333 & 0.0833333 & 1 & & \\
\hline NS5 & $\sim A^{*} B^{*} \sim C^{*} D^{*} E^{*} \sim F^{*} \sim G$ & 0.0833333 & 0.0833333 & 1 & 1 & 1 \\
\hline NS6 & $A^{*} \sim B^{*} C^{*} \sim D^{*} \sim E^{*} \sim F^{*} G$ & 0.0833333 & 0.0833333 & 1 & & \\
\hline NS7 & $\sim A^{*} \sim B^{*} C^{*} D^{*} E^{*} \sim F^{*} G$ & 0.0833333 & 0.0833333 & 1 & & \\
\hline NS8 & $\sim A^{*} B^{*} \sim C^{*} D^{*} E^{*} F^{*} G$ & 0.0833333 & 0.0833333 & 1 & & \\
\hline NS9 & $A^{*} \sim B^{*} C^{*} D^{*} E^{*} F^{*} G$ & 0.0833333 & 0.0833333 & 1 & & \\
\hline
\end{tabular}

Source: generated by the fsQCA software.

TABLE 7: Combination of conditions to reach the peak of public opinion before the reversal.

\begin{tabular}{|c|c|c|c|c|c|c|c|c|c|}
\hline Variable & S1 & S2 & S3 & S4 & S5 & S6 & S7 & S8 & S9 \\
\hline$A$ & 0 & & $\bullet$ & 0 & 0 & 0 & & 0 & $\otimes$ \\
\hline$B$ & & $\otimes$ & • & $\otimes$ & - & • & - & $\otimes$ & - \\
\hline$C$ & $\bullet$ & $\bullet$ & $\bullet$ & $\bullet$ & & $\bullet$ & $\bullet$ & $\otimes$ & $\otimes$ \\
\hline$D$ & - & $\otimes$ & • & $\otimes$ & $\otimes$ & & • & $\otimes$ & • \\
\hline$E$ & $\otimes$ & ○ & $\otimes$ & • & $\otimes$ & • & $\otimes$ & $\otimes$ & • \\
\hline$F$ & & $\otimes$ & $\otimes$ & & • & $\otimes$ & ○ & $\otimes$ & $\otimes$ \\
\hline$G$ & - & - & & $\bullet$ & • & - & - & - & • \\
\hline CS & - & & - & ○ & ○ & • & & ○ & $\otimes$ \\
\hline $\mathrm{CV}$ & 0.222 & 0.167 & 0.111 & 0.111 & 0.111 & 0.167 & 0.111 & 0.056 & 0.111 \\
\hline $\mathrm{NCV}$ & 0.111 & 0.111 & 0.056 & 0.056 & 0.111 & 0.167 & 0.056 & 0.056 & 0.111 \\
\hline OCS & & & & & 1 & & & & \\
\hline $\mathrm{OCV}$ & & & & & 1 & & & & \\
\hline
\end{tabular}

Source: generated by the fsQCA software.

* netizens' questions and media follow-up reports $*$ the central government's response has played a core element in this path. This path means that when an emergency event involving personal safety and economic interests occurs, the event information is displayed online for the first time by carriers such as traditional media or online media, 
TABLE 8: Combination of conditions to reach the peak of public opinion after the reversal.

\begin{tabular}{|c|c|c|c|c|c|c|c|c|c|}
\hline Variable & NS1 & NS2 & NS3 & NS4 & NS5 & NS6 & NS7 & NS8 & NS9 \\
\hline $\bar{A}$ & - & $\otimes$ & $\otimes$ & - & $\otimes$ & - & $\otimes$ & $\otimes$ & - \\
\hline$B$ & - & • & $\bullet$ & $\otimes$ & • & $\otimes$ & $\otimes$ & $\bullet$ & $\otimes$ \\
\hline C & $\otimes$ & $\otimes$ & $\bullet$ & $\otimes$ & $\otimes$ & $\bullet$ & • & $\otimes$ & $\bullet$ \\
\hline$D$ & $\otimes$ & & $\bullet$ & $\bullet$ & $\bullet$ & $\otimes$ & $\bullet$ & • & - \\
\hline$E$ & $\otimes$ & $\otimes$ & $\otimes$ & - & $\bullet$ & $\otimes$ & $\bullet$ & • & $\bullet$ \\
\hline$F$ & $\otimes$ & $\otimes$ & $\otimes$ & $\otimes$ & $\otimes$ & $\otimes$ & $\otimes$ & $\bullet$ & $\bullet$ \\
\hline$G$ & & $\bullet$ & $\otimes$ & $\otimes$ & $\otimes$ & $\bullet$ & $\bullet$ & $\bullet$ & $\bullet$ \\
\hline CS & $\bullet$ & $\otimes$ & $\otimes$ & • & $\otimes$ & $\bullet$ & $\otimes$ & $\otimes$ & • \\
\hline $\mathrm{CV}$ & 0.250 & 0.167 & 0.083 & 0.083 & 0.083 & 0.083 & 0.083 & 0.083 & 0.083 \\
\hline $\mathrm{NCV}$ & 0.250 & 0.167 & 0.083 & 0.083 & 0.083 & 0.083 & 0.083 & 0.083 & 0.083 \\
\hline OCS & & & & & 1 & & & & \\
\hline OCV & & & & & 1 & & & & \\
\hline
\end{tabular}

Source: generated by the fsQCA software. CS: consistency; CV: coverage; NCV: net coverage; OCS: overall consistency; OCV: overall coverage.

followed by questions from netizens, follow-up reports by the media, and responses from the central government [14]. Under the circumstances, the emergency is reversed, and the public opinion of the emergency also reaches its climax before the reversal. For example, Shuanghuanglian oral liquid can prevent emergencies such as the new coronavirus, 460,000 square meters per square meter in the Beijing school district, "kidney loss? Kidney atrophy?" incidents, incidents of gauze left in the abdomen of pregnant women in Shandong, and violent attacks on police at Qing'an Railway Station in Heilongjiang. Events are typical representatives of this path. In these emergencies involving personal safety and economic interests, media presentations, netizens questioning, and faster government response have driven the reversal of public opinion. The reversal of public sentiment still reaches its peak before the reversal.

3.4. Robustness Test. This paper mainly tests the robustness of the conditional configuration that promotes the reversal of public opinion to reach the highest peak before the reversal by improving the consistency level. The consistency threshold is adjusted from 0.8 to 0.9 , and the configuration relationship and the number of configuration paths do not occur. It shows that the analysis results are robust [15].

\section{Conclusion}

According to the analysis of the driving path of public opinion reversal in the network of public emergencies obtained above and the analysis of different condition combination paths, the following conclusions can be drawn:

First, the role of opinion leaders in the reversal of public opinion in public emergencies is limited [16]. From Tables 7 and 8 , it can be seen that in the combination of $\mathrm{S} 1 \sim \mathrm{S} 9$, opinion leaders exist in the way of nonparticipation as the core condition, which shows that in the event of reversing public opinion, the participation of opinion leaders is not the main factor for the outbreak of public opinion. Second, the central media's role in reversing public opinion in public emergencies is critical [17]. From the univariate necessity analysis, it can be known that the central media response is a necessary condition for the outcome variable, which shows that the central media response is the key force in the reversal of public opinion dissemination to a climax in public emergencies. Third, we need to be vigilant about the dissemination of images and texts in the reversal of public opinion in public emergencies. The source form of public opinion is in the combination of $\mathrm{S} 1 \sim \mathrm{S} 9$, and the form of graphic and text is spread on the combination of six paths, indicating that the form of graphic and text will boost the spread of public opinion on the reversal event. Fourth, the first issuers in the reversal of public opinion in public emergencies need to strengthen the gate audit [18]. In all the case combinations, the first issuer as the core condition appears in 17 combination paths, which shows that the first issuer is an important factor affecting the reversal of public opinion in public emergencies.

\section{Data Availability}

The datasets used and/or analyzed during the current study are available from the corresponding author on reasonable request.

\section{Conflicts of Interest}

The authors declare that they have no conflicts of interest.

\section{Acknowledgments}

This work is supported by the National Natural Science Foundation of China (71874052), the Hunan Natural Science Foundation Project (No. 2021JJ30367), the Hunan Postgraduate Research Innovation Funding Project (number QL20210160), and the Hunan Science and Technology Innovation Talent Program Project (number 2021RC1004). 


\section{References}

[1] W. Huang, X. Zhao, and J. Zhao, "Analysis of the generation mechanism of reversal events in the high period of public opinion communication," Information Theory and Practice, vol. 42, no. 12, pp. 60-66, 2019.

[2] S. Song, Z. Guo, and X. Wang, "Retracted article: the correlation between social transformation economic risk and Internet public opinion," Behaviour \& Information Technology, vol. 40, no. 7, pp. 723-733, 2021.

[3] X. G. Chen, S. Duan, and L. D. Wang, "Research on clustering analysis of Internet public opinion," Cluster Computing, vol. 22, no. S3, pp. 5997-6007, 2019.

[4] Y. Lian, Y. J. Liu, and X. F. Dohg, "Topological evolution of the Internet public opinion," Physica, A. Statistical Mechanics and its Applications, vol. 486, pp. 567-578, 2017.

[5] Y. X. Zhang, Z. Xu, Z. Hao, and H. Liao, "Dynamic assessment of Internet public opinions based on the probabilistic linguistic Bayesian network and prospect theory," Applied Soft Computing, vol. 106, article 107359, pp. 1568-4946, 2021.

[6] Y. C. Lin, H. Y. Nie, Y. L. Li, and Y. B. Wu, "Internet public opinion monitoring in public health emergencies may benefit from artificial intelligence," Medical Data Mining, vol. 4, no. 3, p. 2624, 2021.

[7] X. Gao and L. Fu, "Methods of uncertain partial differential equation with application to Internet public opinion problem," Journal of Intelligent \& Fuzzy Systems, vol. 33, no. 3, pp. 14231433, 2017.

[8] J. Gong, H. Wan, K. Geng, and M. Wang, "Study on emergency management mechanism of public health emergencies," Meteorological and Environmental Research, vol. 12, no. 2, pp. 34-37, 2021.

[9] Y. Kim, K. Lee, S. S. Oh, and H. Park, "Effectiveness of emergent ad hoc coordination groups in public health emergencies," Risk Analysis: An International Journal, vol. 21, no. 1, pp. 57-78, 2017.

[10] J. Goldsmith, Y. Sun, L. P. Fried, J. Wing, G. W. Miller, and K. Berhane, "The emergence and future of public health data science," Public Health Reviews, vol. 42, pp. 1-6, 2021.

[11] A. Davis, A. Javernick-Will, and S. M. Cook, "The use of qualitative comparative analysis to identify pathways to successful and failed sanitation systems," Science of the Total Environment, vol. 663, no. 1, pp. 507-517, 2019.

[12] H. S. Sethi and K. Naik, "Comparative analysis of coaxial phacoemulsification with 2.2- and 2.8-mm clear corneal incisions," International Ophthalmology, vol. 38, no. 1, pp. 215222, 2017.

[13] B. Ma, Q. Tan, and D. Ping, "Public opinion and social justice in China," Journal of Chinese Political Science, vol. 45, no. 2, pp. 1-18, 2021.

[14] M. Ren, G. Andrea, R. Carla Anne, P. Tom, and K. Namkje, "Private-public opinion discrepancy," PLoS One, vol. 15, no. 11, article e0242148, pp. 1-24, 2020.

[15] L. Chen, J. Chen, and C. Xia, "Social network behavior and public opinion manipulation," Journal of Information Security and Applications, vol. 64, no. 10, article 103060, pp. 25-34, 2022.

[16] J. Sevenans, "How public opinion information changes politicians opinions and behavior," Political Behavior, vol. 43, no. 4, pp. 1801-1823, 2021.
[17] C. Meyer, H. Kenneth, C. C. Michael, and G. Jeffrey, “The emergence of public administration as a tool for public management," Journal of Business \& Educational Leadership, vol. 9, no. 1, pp. 4-16, 2019.

[18] T. Chen, Y. Wang, J. Yang, and G. Cong, "Modeling public opinion reversal process with the considerations of external intervention information and individual internal characteristics," Healthcare (Basel)s, vol. 8, no. 2, p. 160, 2020. 